\title{
ANALYSIS OF SELF MEDICATION PRACTICES; A DESCRIPTIVE CROSS SECTIONAL STUDY
}

1. Community Medicine Deptt, Foundation University Medical College, Islamabad.

$2,3,4,5,6$

Students of $4^{\text {th }}$ year MBBS,

Foundation University Medical College.

Correspondence Address:

Dr. Shumaila Humayun

Demonstrator

Community Medicine Deptt

$H \# 21$, St\#12, Sector E,

DHA Phase 1, Islamabad

shumailahn@gmail.com

Article received on:

02/01/2016

Accepted for publication:

15/03/2016

Received after proof reading:

04/05/2016

\begin{abstract}
Dr. Shumaila Humayun ${ }^{1}$, Warda Imran², Iram Naheed ${ }^{3}$, Nazish Javid ${ }^{4}$, Misbah Hussain ${ }^{5}$, Maheen Azhar
ABSTRACT... Background: Worldwide practice of self-medication is increasing and due to lack of awareness emphasis is put on counseling of general public. Aim: To assess the practices of self-medication among general public. Design: Descriptive cross sectional study. Place and duration of study: Fauji Foundation Hospital, Rawalpindi from February 2015 to September 2015. Methods: Two hundred and fifty five attendants accompanying patients in general OPD of Fauji Foundation Hospital completed a self-administered questionnaire translated in urdu language for this study. Results: Out of 255 study participants, 168 (or $65.9 \%$ ) practiced selfmedication. The prevalence was found highest among 25 to 38 years old $(70.2 \%)$ and was almost equally distributed in males $65(65.65 \%)$ and females $103(66.02 \%)$. The main reasons for self-medication were lack of time (43.45\%), and high doctor fee (35.71\%).Factors influencing this practice were age, employment, income and the education level. Conclusions: The study revealed that prevalence of self-medication was high among study population. Majority of respondents practiced self-medication for minor ailments and to get quick relief, or to avoid high doctor fee. Pharmacies are a big source of providing drugs for self-medication. There is need for healthcare professionals to educate the general public about the hazards of inappropriate medicine use, and there should be restrictions on over-the-counter sale of drugs without doctor's prescription.
\end{abstract}

Key words: Analysis, Self-Medication, Minor ailments, Over-the-counter, Cross sectional, Descriptive Study.

Article Citation: Humayun S, Imran W, Naheed I, Javid N, Hussain M, Azhar M. Analysis of self-medication practices; a descriptive cross sectional study. Professional Med J 2016;23(5):608-613. DOI: 10.17957/TPMJ/16.3239

\section{Statement of Novelty}

The phenomenon of self-medication has been studied in various segments of society but intensive and extensive literature survey indicates none of the studies conducted in Northern area of Pakistan especially in the Pothohaar Region. The study fills an identified gap in the body of knowledge and proves to be a contribution to the domain of public health.

\section{INTRODUCTION}

Self-medication is the use of medicines by individuals (or for family members of individual) to treat self-recognized or self-diagnosed conditions or symptoms. [1] It means obtaining and using drugs without the advice or recommendation of a physician either for diagnosis, prescription or surveillance of treatment or usage of nonprescription medicines by people totally on their own. ${ }^{1}$ Self-medication is a common and an important health problem worldwide due to its universal acceptance especially in under developed countries or where proper drug regulation systems or laws are not present or not implicated. This encourages individuals to treat minor illnesses by using simple and effective remedies through self-medication without a doctor's visit, thus saving time and doctor's fee. These minor illnesses include pain, diarrhea, constipation, gastric acid hyper secretion, or allergic diseases. $^{2}$

The list of responsible factors shown in different studies includes lifestyle, access to drugs, the potential to manage certain illnesses through self-care, and greater availability of medicinal products. $^{3}$ It is generally accepted that selfmedication has an important part in health 
care. By improving people's education, general knowledge and socio-economic status; selfmedication can decrease the burden on hospital OPD. It has been successfully implicated into many health care systems throughout the world. ${ }^{4}$ But there is also the risk for misuse and abuse of such drugs. Misuse here is defined as taking an over-the-counter drug for a genuine medical condition but in higher doses or for a longer period than prescribed, like taking excess amount of a painkiller than prescribed for treatment of headache. Abuse is using nonmedical over-thecounter drugs, e.g. to gain or lose weight. ${ }^{5}$

Several studies on the subject show that there are risks like misdiagnosis, drug resistance or increased pathogen resistance, and use of drugs in excessive amounts, use of expired drugs, long time use, drug interactions and poly-pharmacy ${ }^{6}$ in self-medicating people. It is predicted that more than $50 \%$ of antibiotics globally are bought privately without prescription, from pharmacies or street vendors. ${ }^{7,8}$ e.g. Chlorpheniramine is an over the counter drug easily accessible in Pakistan which is a substance of misuse and abuse among the truck drivers. ${ }^{9}$ Taking medications on their own is common practice these days and the prevalence is high around the globe $\mathrm{e}^{10,11}$ up to $68 \%$ in European countries,92\% in Kuwait,59\% in Nepal and $31 \%$ in India, while a previous study in Pakistan shows $51 \%$ prevalence.

The purpose of this study was to analyze the selfmedication practices in general population and to identify the determinants of self medication, as there is no current study available in this region. ${ }^{12}$

\section{METHODS}

Cross sectional study was conducted in General OPD of Fauji Foundation Hospital, Islamabad, affiliated with Foundation University Medical College, from February 2015 to September 2015 after pilot testing through closed ended structured questionnaire translated in Urdu. 255 consenting male and female attendants aged $>18$ years, in $\mathrm{FFH}$ general OPD were included in the study and they were selected by convenient sampling. Only currently non diseased adults were subjects of our study hence less than 18 year old subjects were excluded, as well as patients, and hospital staff was excluded from study. The respondents were self-interviewed by the research group students of fourth year MBBS. After collection of data it was checked for omissions and mistakes and it was cleaned and only necessary data was entered in SPSS 17. Data analysis results for this study were mainly done in frequencies and percentages. In order to calculate the differences in self-medication practice by gender, chi-square test was applied and p-value of less than 0.05 was taken as significant.

\section{RESULTS}

The results showed that among 255 attendants accompanying the patients in general OPD, $99(38.8 \%)$ were males and $156(61.2 \%)$ were females. Majority belonged to the age group of 25-31yrs.Almost $50 \%$ were unemployed. There were $21.6 \%$ illiterate while $88 \%$ literate subjects. About $40 \%$ were from rural area while $60 \%$ belonged to urban and suburban residence. A great majority $65.9 \%$ self-medicated of which 73 (43.45\%) self-medicated due to lack of time and $60(35.71 \%)$ due to high doctor fee. Our results show that self-medication practice was more common in urban areas (71.24\%). 29\% used homeopathic, $4.7 \%$ used ayurveda, $12.2 \%$ used Hakeem and $54.1 \%$ used allopathic system of medicines. Self-medication was mainly done for symptoms of runny nose (50\%).Moreover, $15.47 \%$ used the medicines for skin wounds, $16.07 \%$ used them for cough, $4.2 \%$ used them for joint pains, $9.52 \%$ used them for fever, $3.57 \%$ used them for headaches and $1.2 \%$ used them for acidity. About $47.02 \%$ said that their medicine selection was based on chemists' recommendation. Others based their medicine selection on opinion of family members $(26.19 \%)$, opinion of friends (14.88\%), self-experience (9.52\%), internet $(1.78 \%)$ and pervious doctor's prescription (0.59\%). $60.8 \%$ did not change the medicine, $63.9 \%$ did not change dosage of drug, $47.62 \%$ switched to other medicines and $51.19 \%$ never completed the recommended course of medicine. $60.12 \%$ developed adverse reactions to drug. Around $51.4 \%$ think self-medication is a 
good and successful practice. $54.5 \%$ check the expiry dates and $31.4 \%$ of them receive these medicines from hospitals. Rest of them obtains the medicines from community pharmacies (24.3\%), leftover from previous prescription (29.8\%), online shopping/E-pharmacy (10.2\%) and other sources (4.3\%). Only $51.8 \%$ read the instructions. Thus it revealed that the prevalence is high in Pakistan and the main factors influencing self-medication are age, employment, and income and education level.

\begin{tabular}{|c|c|c|}
\hline Self-medicated & Frequency & $\%$ \\
\hline Yes & 168 & 65.9 \\
\hline No & 87 & 34.1 \\
\hline Reason & $\begin{array}{l}\text { Frequency } \\
\qquad(n=168)\end{array}$ & $\%$ \\
\hline High doctor fee & 60 & 35.7 \\
\hline Lack of time & 73 & 43.4 \\
\hline For quick relief & 30 & 17.9 \\
\hline Confidence in myself & 5 & 3 \\
\hline Selection of medicine & Frequency & $\%$ \\
\hline Recommendation by chemist & 79 & 47.02 \\
\hline Opinion of family members & 44 & 26.2 \\
\hline Opinion of friends & 25 & 14.88 \\
\hline My own experience & 16 & 9.52 \\
\hline Internet & 3 & 1.78 \\
\hline $\begin{array}{l}\text { Previous doctor's } \\
\text { prescription }\end{array}$ & 1 & 0.59 \\
\hline $\begin{array}{l}\text { Conditions For Which Self } \\
\text { medicated }\end{array}$ & Frequency & $\%$ \\
\hline Runny nose & 84 & 50 \\
\hline Skin wounds & 26 & 15.47 \\
\hline Cough & 27 & 16.07 \\
\hline Joint pains & 7 & 4.2 \\
\hline Fever & 16 & 9.52 \\
\hline Headache & 6 & 3.57 \\
\hline Acidity & 2 & 1.2 \\
\hline \multicolumn{3}{|c|}{$\begin{array}{l}\text { Table-I. Frequencies of self-medication in consenting } \\
\text { attendants greater than } 18 \text { years old in FFH general } \\
\text { OPD }(n=255)\end{array}$} \\
\hline
\end{tabular}

\section{INTERPRETATION OF CHI-SQUARE TEST}

$\mathrm{HO}$ : There is no significant difference between the practice of self-medication among males and females.

$\mathrm{H} 1$ : $\quad$ There is a significant difference between the practice of self-medication among males and females.

$P$ Value: 0.952 .

Level of Significance: 0.05 .

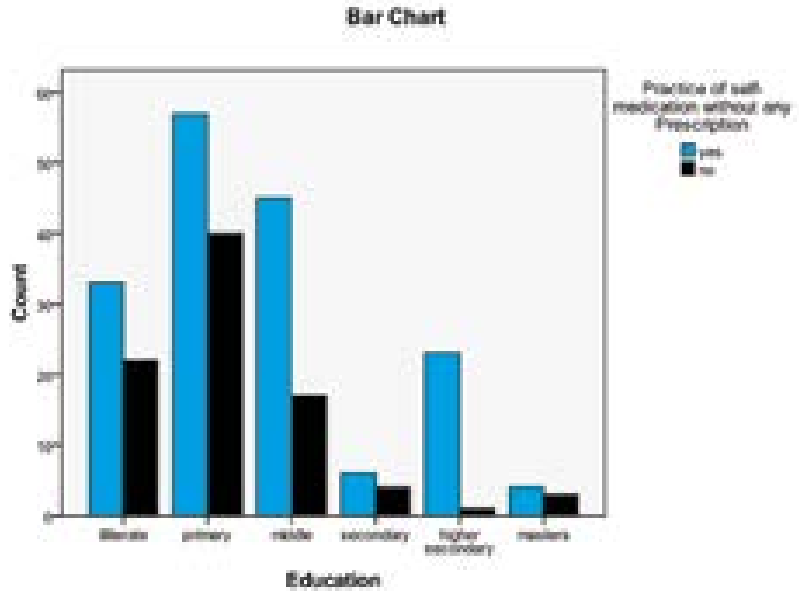

Figure-1. Cross tabulation of educational status with self-medication

The application of Chi-square Test indicates that $P$ value has been 0.952 that is higher than the level of significance that is 0.05 hence accepting the null hypothesis and rejecting the alternate hypothesis. The results of the analysis indicate the peculiar socioeconomic structure of this society where accessibility to medical facilities gets restricted due to low income per capita and it equally affects male and female population.

\section{DISCUSSION}

This is a questionnaire based descriptive study on self-medication which was completely based on the information given by respondents in outpatient department of Fauji Foundation Hospital Rawalpindi. A total of 255 attendants participated in this study. Out of 255, 99 (38.8\%) were male and $156(61.2 \%)$ female. Majority (65.9\%) people were observed to practice selfmedication. Another research in Islamabad ${ }^{13}$ which was conducted on 500 respondents showed that $61.2 \%$ people self-medicated. It is higher than Hong Kong China (32.5\%) while lower than Slovenia (92.3\%).

According to our study self-medication was mostly practiced by young people belonging to age group $25-31$ years $(47.1 \%)$. This result is in line with study named attitude and practice towards self-medication among resident of Ikeja 20- 29(47.5\%). ${ }^{14}$ 


\begin{tabular}{|c|c|c|c|c|c|}
\hline \multicolumn{6}{|c|}{ Gender * Practice of self-medication without any prescription Cross tabulation } \\
\hline & & & \multicolumn{2}{|c|}{$\begin{array}{c}\text { Practice of self-medication without any } \\
\text { prescription }\end{array}$} & \multirow{2}{*}{ Total } \\
\hline & & & yes & no & \\
\hline \multirow{4}{*}{ Gender } & \multirow{2}{*}{ male } & Count & 65 & 34 & 99 \\
\hline & & Expected Count & 65.2 & 33.8 & 99.0 \\
\hline & \multirow{2}{*}{ female } & Count & 103 & 53 & 156 \\
\hline & & Expected Count & 102.8 & 53.2 & 156.0 \\
\hline \multirow{2}{*}{\multicolumn{2}{|c|}{ Total }} & Count & 168 & 87 & 255 \\
\hline & & Expected Count & 168.0 & 87.0 & 255.0 \\
\hline
\end{tabular}

\begin{tabular}{|c|c|c|c|c|c|}
\hline & Value & df & Asymp. Sig. (2-sided) & Exact Sig. (2-sided) & Exact Sig. (1-sided) \\
\hline Pearson Chi-Square & $.004^{a}$ & 1 & .952 & & \\
\hline Continuity Correction ${ }^{b}$ & .000 & 1 & 1.000 & & \\
\hline Likelihood Ratio & .004 & 1 & .952 & & \\
\hline Fisher's Exact Test & & & & 1.000 & .529 \\
\hline Linear-by-Linear Association & .004 & 1 & .952 & & \\
\hline $\mathrm{N}$ of Valid Cases & 255 & & & & \\
\hline \multicolumn{6}{|c|}{ a. 0 cells $(0.0 \%)$ have expected count less than 5 . The minimum expected count is 33.78 . } \\
\hline \multicolumn{6}{|c|}{ b. Computed only for a $2 \times 2$ table. } \\
\hline \multicolumn{6}{|c|}{ CHI-SQUARE TEST } \\
\hline
\end{tabular}

Our results show that self-medication practice is more common in urban areas (71.24\%).Similar response is seen in Islamabad ${ }^{15}$ in a study which reveals high prevalence rate in urban subjects, $68.3 \%$. There is a similar pattern in a study from India; however in Srilanka the prevalence in rural areas was higher than urban areas. It is not unexpected that due to the unsatisfactory medical care, people with busy urban lifestyle use self-medication as alternative especially in mild illnesses.

In our study mostly people practiced selfmedication because of lack of time 73 (43.45\%) and high doctor fee 60 (35.71\%) it can be compared with study in Bangladesh [16] which shows the same reason for self-medication practice as high doctor fee (42\%) and not having enough time (32\%).In this study we found that $(54.1 \%)$ of population use Allopathic system of medication, people (29\%) showed trust on homeopathic on Ayurveda (4.7\%) and on Hakeem (12.2\%) These results can be compared with a study done in Karachi, Pakistan ${ }^{17}$ in which $64.7 \%$ used allopathic system.

(54.1\%) people favored the self-medication practice as it is convenient and provides quick relief. Our results are in line with study in Ethiopia $^{18}$ where $(55 \%)$ respondents agree with self-medication practice.

Our study shows that majority of the respondents $31.4 \%$ took medicine from hospital and $29.8 \%$ used left over drugs. It can be further compared by another study at Saudi Arabia ${ }^{19}$ where (80\%) respondents identified that pharmacy was a major source for both drugs and information. This is probably due to weak enforcement of regulation regarding drug handling and dispensing. Consequently salesmen of pharmacies are commonly considered as major source of medicine without prescription.

\section{CONCLUSION}

The study revealed that prevalence of selfmedication in this area is high among sample population. The main factors influencing self- 
medication are age, income, and employment and education level. According to our study majority of respondents practiced self-medication for minor ailments and to get quick relief. People also self-medicated because of lack of time and high doctor fee. Pharmacies were a big source of providing drugs for self-medication. Pharmacists should be more attentive towards people who take medicines without prescription. This is an alarming sign as an indiscriminative use of drugs can lead to various drug interactions and side effects. There is need for healthcare professionals to familiarize the consumers with problems of inappropriate medicine use through public education. There is dire need for enforcement of regulations on over-the-counter availability of drugs, and constant surveillance of pharmacies.

Copyright@ 15 March, 2016.

\section{REFERENCES}

1. Mumtaz $\mathrm{Y}$, Jahangeer SMA, Mujtaba T, Zafar S, Adnan $S$. Self-Medication among University Students of Karachi. Journal of Liaqat University of Medical and Health Sciences. 2011; 10: 102.

2. Amin S, Abid F, Javeed A, Ashraf M, Riaz A, Mushtaq MH, Ghafoor A, Anees M, Yaqoob M. A Crosssectional study on Self-medication with analgesics among pharmacy students of Lahore, Pakistan. Sci. Int. (Lahore). 2014; 26(3): 1181.

3. Bushra Ali Sherazi et al. Prevalence and Measure of Self Medicine: A Review. Journal of Pharmaceutical Sciences and Research. 2012; 4(3): 1775.

4. The benefits and risks of self-medication. WHO Drug Information. 2000; 14: 1.

5. Cooper RJ. Over-the-counter medicine abuse - a review of the literature. Journal of Substance Use. 2013; 18: 82-107.

6. Hughes $\mathrm{CM}$, McElnay JC, Fleming GF: Benefits and risks of self-medication. Drug Saf. 2001; 24: 10271037.

7. Cars O, Nordberg P. Antibiotic resistance -The faceless threat. The International Journal of Risk and
Safety in Medicine. 2005; 17: 103-10.

8. Togoobaatar G, Ikeda N, Ali M, Sonomjamts M, Dashdemberel S, Mori R \& Shibuya K. Survey of nonprescribed use of antibiotics for children in an urban community in Mongolia. Academic Journal. 2010; 88: 877-953.

9. Kunin CM. Resistance to antimicrobial drugs-A Worldwide Calamity. Ann Intern Med. 1993;118:557561.

10. Zafar SN, Syed R, Waqar S, Zubairi AJ, Vaqar T. Selfmedication amongst university students of Karachi: prevalence, knowledge and attitudes. Journal of Pakistan Medical Association. 2008; 58(4): 214-7

11. Baig QA, Muzaffer D, Afaq A, Bilal S, Iqbal N. Prevalence of self medication among dental patients. Pak Oral Dent J 2012;32:292-5.

12. Hussain A, Khanum A. Self-Medication among University students of Islamabad, Pakistan- A preliminary study. Southern Med Review,2008;1(1):14-16.

13. Aqeel T, Shabbier A, Basharat $H$, Bukhari M, Mobin $S$, Shahid $H$, \&Waqar SA. Prevalence of Self-Medication among Urban and Rural Population of Islamabad, Pakistan. Tropical Journal of Pharmaceutical Research.2014;13(4): 627-633.

14. Kuku K, Odusanya O. Attitude and Practices towards Self Medication among residents of Ikeja. 2011; 2 .

15. Ira IJ. Present condition of self-medication among general population of Comilla district, Bangladesh. The Pharma Innovation Journal. 2015;4(1): 87-90.

16. Ali SM, Fatima M, Ali L. Self-medication among downtown urban population of Karachi, Pakistan. Indian Journal of Medical Research and Pharmaceutica Sciences. 2015;2(4):17-24.

17. Abay SM, Amelo W. Assessment of Self-Medication Practices among Medical, Pharmacy, and Health Science Students in Gondar University, Ethiopia. J Young Pharm. 2010;2(3):306-310.

18. Alghanim SA. Self-medication practice among patients in a public health care system. Eastern Mediterranean Health Journal. 2011;17(5):409-416. 


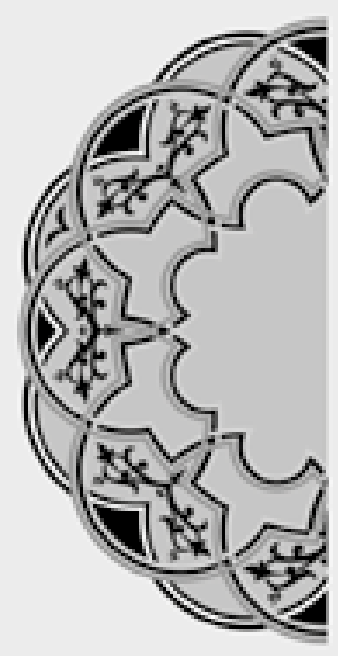

\title{
"If you want to live a happy life, tie it to a goal. Not to people or things."
}

\author{
Albert Einstein
}

\begin{tabular}{|c|c|c|c|}
\hline \multicolumn{4}{|c|}{ AUTHORSHIP AND CONTRIBUTION DECLARATION } \\
\hline Sr. \# & Author-s Full Name & Contribution to the paper & Author $=$ s Signature \\
\hline 1 & Dr. Shumaila Humayun & $\begin{array}{l}\text { Principal investigator topic } \\
\text { selection \& data analysis } \\
\text { \& interpretation }\end{array}$ & \\
\hline 2 & Warda Imran & $\begin{array}{l}\text { Co-investigaters \& data } \\
\text { collection }\end{array}$ & \\
\hline 3 & Iram Naheed & $\begin{array}{l}\text { Co-investigaters \& data } \\
\text { collection }\end{array}$ & \\
\hline 4 & Nazish Javid & $\begin{array}{l}\text { Co-investigaters \& data } \\
\text { collection }\end{array}$ & \\
\hline 5 & Misbah Hussain & $\begin{array}{l}\text { Co-investigaters \& data } \\
\text { collection }\end{array}$ & \\
\hline 6 & Maheen Azhar & $\begin{array}{l}\text { Co-investigaters \& data } \\
\text { collection }\end{array}$ & \\
\hline
\end{tabular}

